\section{Development of a Sensitive, Highly Controlled Assay for Molecular Detection of the Philadelphia Chromosome in Patients with Chronic Myelogenous Leukemia}

\author{
MARTIN J. HESSNER, \\ MARK S. ROTH, \\ WILLIAM R. DROBYSKI, and \\ LEE ANN BAXTER-LOWE
}

The Philadelphia chromosome (Ph1), present in $\geqslant 95 \%$ of chronic myelogenous leukemia (CML) patients, is a well-characterized translocation that results in a unique chimeric gene product (BCR/ABL) with transforming capability. Molecular methods utilizing the polymerase chain reaction (PCR) to detect $\mathrm{BCR} / \mathrm{ABL} m R N A$ transcripts has been useful for detecting minimal residual disease (MRD) after treatment, as well as for establishing the diagnosis of CML. Amplification-based assays for the $\mathrm{BCR} / \mathrm{ABL}$ transcript, however, have shown variable reproducibility and sensitivity. This variability may be largely due to technical differences and insufficient controls. In this report, we describe the development of a highly controlled, reproducible, and sensitive PCR assay to detect $P$ hl that is well suited to clinical and research applications. A validation study of 82 samples was performed consisting of 25 dilutions of $K 562$ cells $(P h 1+)$ into normal cultured $B$ cells, 26 pre-and posttransplant peripheral blood samples from CML patients, 16 peripheral blood samples for diagnosis of $C M L$, and 15 peripheral blood samples from healthy individuals. RNA isolated from 3 to 5 million leukocytes was reverse transcribed $(R T)$ and amplified by nested primer PCR. The products were characterized using agarose gel electrophoresis. Approximately 1000 Phlpositive cells admixed with $10^{6}$ normal cells were de-

From the Blood Center of Southeastern Wisconsin (M.J.H., L.A.B-L.), Milwaukee, Wisconsin; the University of Michigan Medical School (M.S.R.), Ann Arbor, Michigan; and the Medical College of Wisconsin (W.R.D., L.A.B-L.), Milwaukee, Wisconsin, USA.

Address correspondence to Dr. M.J. Hessner, The Blood Center of Southeastern Wisconsin, 1701 West Wisconsin Avenue, Milwaukee, WI 53233.

Received 25 February 1994; accepted 17 May 1994. tectable after one round of amplification. In $60 \%$ of assays where one Phl-positive cell was admixed with $10^{6}$ normal cells, a $\mathrm{BCR} / \mathrm{ABL}$ product was detectable after nested primer PCR. Specific measures to ensure accurate results in routine testing included (a) assessing $R N A$ integrity and adequate cDNA preparation by detection of the constitutively expressed ABL $m R N A,(b)$ monitoring sensitivity with the addition and detection of K562 RNA mixed with RNA from unknown samples (failure to detect the "spiked" K562 RNA indicates the presence of inhibitors or ribonucleases within the unknown RNA sample), (c) detection of nucleic acid contaminants by using negative controls in every assay, and (d) duplicate analysis of all samples and controls. Internally, this assay was $100 \%$ reproducible. Our results verify that nested primer RT-PCR is a fast, sensitive alternative to cytogenetic or Southern blot analysis for monitoring MRD after treatment and for diagnosis of CML. In addition, the highly controlled detection scheme presented here can be used as a general model for the development of other amplification-based detection assays.

\section{Introduction}

The Philadelphia chromosome (Ph1) is a truncated derivative of chromosome 22 that arises through a reciprocal translocation involving the long arms of chromosomes 9 and 22 and is observed in $\sim 95 \%$ of chronic myelogenous leukemia (CML) patients. A chimeric gene, $B C R / A B L$, is generated through the translocation of the upstream region of the $B C R$ gene (located on chromosome 22) to the $A B L$ gene (located on chromosome 9). Breakpoints on chromosome 9 occur within a wide region, in $>200$ kilobases (kb), extending from exon 2 of $A B L$ to a distance $5^{\prime}$ of the entire gene. Breakpoints on chromosome 22 occur intronically clustered near the middle the $B C R$ gene, within a five-exon region designated the major breakpoint cluster region (M-BCR). Although the DNA breakpoints within the $B C R$ and $A B L$ genes are variable, RNA splicing results in precise exon joining. In CML cells, this hybrid mRNA consists of $B C R$ exon $2 / A B L$ exon 2 (B2A2) and/or $B C R$ exon $3 / A B L$ exon 2 (B3A2) fusions. This $8.5-\mathrm{kb}$ transcript is translated into a $210-\mathrm{kD}$ protein $(\mathrm{P} 210)$ with altered tyrosine kinase activity, which is implicated in the progression of CML [1].

Selective amplification of the chimeric $B C R /$ $A B L$ oncogene mRNA transcript using reverse transcription and the polymerase chain reaction (RT-PCR) enables faster and significantly more sensitive detection of Ph1-positive cells than cytogenetic analysis or Southern blotting [2]. These 
alternative techniques require that $\mathrm{Ph} 1$-positive cells comprise at least $1 \%$ of the leukocyte population for detection. RT-PCR Detection of Ph1 has utility as a means of monitoring patients after bone marrow transplant (BMT) for minimal residual disease (MRD). Recent studies have now demonstrated that PCR detection of Ph1-positive cells is valuable in predicting disease progression for CML patients in apparent clinical remission after BMT [3]. These studies have shown that CML patients persistently positive for the $B C R / A B L$ mRNA by RT-PCR after BMT are at significantly greater risk of relapse. Conversely, those CML patients persistently $B C R / A B L$ negative are at a low risk of relapse. Molecular detection of Ph1positive cells can provide information on early relapse although patients remain in cytogenetic and hematologic remission. RT-PCR detection of Phl is also useful in establishing the diagnosis of CML.

Many investigators have reported the use of PCR-based methodologies to monitor Ph1-positive cell populations after BMT [4-10]. A major obstacle surrounding the routine use of PCR for detecting MRD is reproducibility and the potential for false positive and false negative assays. To overcome these problems, we have developed, and describe here, an assay system in which template quality, assay components, and assay sensitivity are internally controlled.

\section{Materials and Methods}

\section{RNA Preparation}

Total cellular RNA was prepared from peripheral blood, peripheral blood buffy coats, or peripheral blood mononuclear cells isolated by FicollHypaque, or cultured B cells and K562 (Ph1positive) cells. Cells were either viably frozen or directly added to $4 \mathrm{M}$ of guanidinium isothiocyanate. RNA was prepared from 3-5 million cells as previously described with minor modifications [11]. Electrophoretic separation of sample RNA preparations through $2 \%$ agarose ethidiumbromide-stained gels revealed that isolations were not free of DNA; however, the relative amount of contaminating DNA was consistent from sample to sample.

\section{Reverse Transcription and PCR}

Figure 1 depicts a schematic representation of the $B C R / A B L \mathrm{mRNA}$ structure and the position of the oligonucleotide primers used for its detection. One microgram of total cellular RNA was reversetranscribed for $1 \mathrm{~h}$ at $42^{\circ} \mathrm{C}$ in $50 \mathrm{mM}$ Tris- $\mathrm{HCl}, \mathrm{pH}$ $8.3,50 \mathrm{mM} \mathrm{KCl}, 8 \mathrm{mM} \mathrm{MgCl}{ }_{2}, 10 \mathrm{mM}$ DTT, 0.5 mM dNTP's, and $2 \mu \mathrm{g} A B L-\mathrm{RT}$ primer using $30 \mathrm{U}$ AMV-RT (Seikagaku America, Rockville, MD, USA) in a total volume of $50 \mu \mathrm{l}$. PCR was performed directly on $10 \mu \mathrm{l}$ of this material in $10 \mathrm{mM}$ Tris- $\mathrm{HCl}, \mathrm{pH} 8.3,50 \mathrm{mM} \mathrm{KCl}, 1.6 \mathrm{mM} \mathrm{MgCl} 2,2$ mM DTT, $0.2 \mathrm{mM}$ dNTP's, and $0.2 \mu \mathrm{g}$ of each of the primers $A B L-1$ and $B C R-1$ using $1 \mathrm{U}$ of Taq polymerase in a total reaction volume of $50 \mu \mathrm{l}$. Thirty-five cycles were performed consisting of $1.25 \mathrm{~min}$ at $94^{\circ} \mathrm{C}$ and $1.5 \mathrm{~min}$ at $72^{\circ} \mathrm{C}$ in a PerkinElmer 480 thermalcycler. All PCRs were terminated after a 10 -min extension at $72^{\circ} \mathrm{C}$. Secondround $\mathrm{PCR}$ was performed using the internally nested primers (BCR-2 and $A B L-2)$ with $1 \mu l$ of the first-round PCR product as template for an additional 35 cycles. The sequences of the oligonucleotide primers $B C R-1, B C R-2, A B L-1, A B L-2$, and $A B L-3$ have been previously described [2]. A total of $15 \mu$ l of each amplified PCR product was analyzed by electrophoresis through $2 \%$ agarose gels and stained with ethidium bromide.

\section{Assay Control}

Specific measures to ensure accurate results in routine testing were incorporated into this assay. All RNA isolations, cDNA synthesis, and all setups (except for introduction of second-round PCR

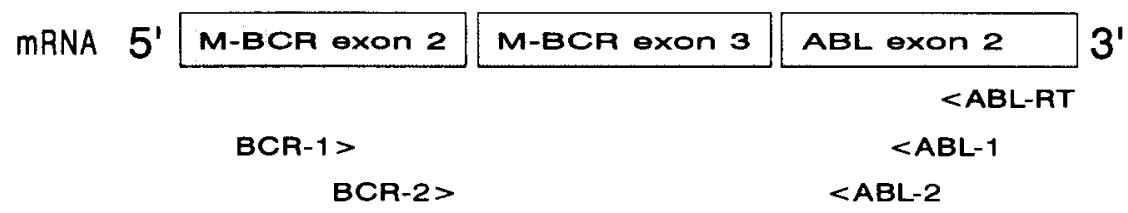

Figure 1. Structure of the B3A2 Ph1 mRNA and locations of primers used for reverse transcription and nested primer PCR. The PCR products generated from a B3A2 Ph1 are $392 \mathrm{bp}$ and $300 \mathrm{bp}$, respectively. The PCR products generated from a B2A2 Ph1 are 75 bp shorter. 
template) were performed in a positive pressure high-efficiency particulate air (HEPA)-filtered clean room to prevent the introduction of previously amplified material. The evaluation of RNA integrity and adequate cDNA synthesis from samples was accomplished through the detection of the constitutively expressed $A B L$ mRNA from the same reverse transcription reaction. The $A B L$ cDNA was amplified using the primers $A B L-1$ and $A B L-3$ (which targets $A B L$ exon la). Assay sensitivity was monitored through the addition and detection of $0.05 \mathrm{ng} \mathrm{K562}$ RNA mixed within a replicate assay for each unknown sample. This RNA quantity represents nucleic acid isolated from $\sim 5$ K562 cells, which requires two rounds of nested primer PCR for detection. Failure to detect the "spiked" K562 RNA could indicate the presence of inhibitors or ribonucleases within the unknown RNA sample. Mock RNA preparations were included in every assay as negative-control RNA to survey the possibility of false positives due to the introduction of previously amplified DNA. All sample and control RNAs were analyzed in duplicate, beginning with independent RNA isolations.

\section{Results and Discussion}

\section{Assay Sensitivity}

Figure 2 shows the sensitivity of $B C R / A B L$ mRNA detection by RT-PCR. Assays were performed using RNA isolated from decreasing numbers of K562 cells mixed with $10^{6}$ normal cultured cells. The K562 cell line possesses the B3A2 Ph1. With one round of PCR it is possible to detect as few as $1000 \mathrm{Ph} 1$-positive cells admixed with 1 million normal cells (Figure 2, lane B2). After the second round of PCR, using the internally nested primers, it is possible to detect as few as one Ph1-positive cell admixed with 1 million normal cells (Figure 2, lane C3).

\section{Assay Validation}

A validation study of 82 samples was performed using 25 prepared dilutions of K562 cells into normal cultured B cells, 26 pre- and posttransplant peripheral blood samples from CML patients, 16 peripheral blood samples for diagnosis of CML, and 15 peripheral blood samples from healthy individuals. Samples were tested in duplicate, with both the ABL positive control and "spiked" K562 positive control; additionally, negative-control samples were included with every assay. The results of this study are provided in Table 1. Dilutions of $\mathrm{K} 562$ cells $\left(10^{6}, 10^{3}, 10\right.$, and 1$)$ mixed with $3 \times 10^{6}$ normal cultured B cells were prepared and tested in a blind manner. The presence of $10^{6}$ and $10^{3} \mathrm{~K} 562$ cells admixed with $3 \times 10^{6}$ normal cultured B cells was detected always in the first and second rounds of PCR. Ten K562 cells admixed with $3 \times 10^{6}$ normal cultured $B$ cells always required two rounds of PCR for detection. One K562 cell admixed with $3 \times 10^{6}$ normal cultured B cells was detected after two rounds of PCR $2 / 5$ times. The bcr/abl oncogene message was never detected in the samples that contained no K562 cells or negative controls.

Samples from 26 pre- and post-BMT patients were assayed for $\mathrm{Ph} 1$ by nested primer PCR at the Blood Center of Southeastern Wisconsin; these samples had also been previously assayed at an independent institution under similar but not identical conditions. A concordance rate of $85 \%(22$

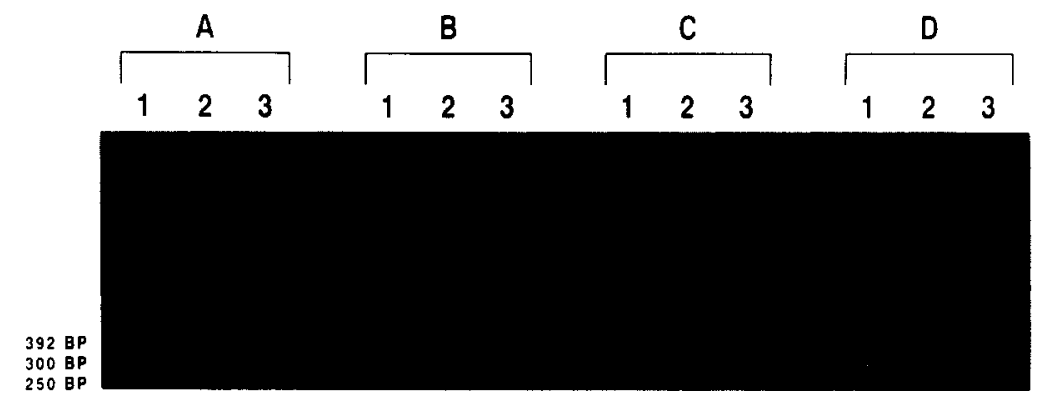

Figure 2. Sensitivity and specificity of nested primer PCR detection of Ph1. All sample sets are run in the following order: (1) ABL control amplification, (2) $B C R / A B L$ first-round amplification, and (3) $B C R / A B L$ second-round amplification. (Set $\mathrm{A}$ ) $10^{6} \mathrm{~K} 562$ cells mixed with $10^{6}$ normal cultured B cells. (Set B) $1000 \mathrm{~K} 562$ cells mixed with $10^{6}$ normal cultured B cells. (Set C) 1 K562 cell mixed with $10^{6}$ normal cultured B cells. (Set D) $10^{6}$ normal cultured B cells. 
Table 1. Results of 82-Sample Validation Study

\begin{tabular}{lccr}
\hline \multicolumn{1}{c}{ Sample set } & No. of samples & \% Reproducible ${ }^{a}$ & $\%$ Concordance $^{b}$ \\
\hline K562/B-cell dilutions & 25 & 100 & $100(25 / 25)$ \\
Pre- and post-BMT samples & 26 & 100 & $85(22 / 26)$ \\
Clinical samples for diagnosis & 16 & 100 & $100(16 / 16)$ \\
Healthy donor samples & 15 & 100 & $100(15 / 15)$ \\
\hline
\end{tabular}

${ }^{a}$ Percent of samples internally reproducible when assayed in duplicate.

${ }^{b}$ Percent of samples in concordance with independent measurements.

samples of 26 patients) was seen within this sample subset; all four discrepancies (two positive and two negative) were in the second round of PCR. When these four samples were previously tested, RNA template was not quantified; therefore, an unknown amount of RNA was surveyed. In assays performed at the Blood Center of Southeastern Wisconsin, however, RNA isolations were quantified, with $1 \mu \mathrm{g}$ of starting nucleic acid always added into reverse transcription reactions. Although nucleic acid isolations at both institutions were similar, the observed discrepancies in this sample subset may have been due to differences in the quantity of RNA surveyed. It is also expected that some assay variability will exist when samples that possess numbers of $\mathrm{Ph} 1$-positive cells near the threshold level of detection are tested. This variability is partly controlled by duplicate testing of all samples from independent RNA isolations.

Sixteen pretreatment/transplant peripheral blood samples were provided for analysis by local hematologists and oncologists. In all 16 cases, there was $100 \%$ concordance between the molecular analysis by nested primer RT-PCR and cytogenetic analysis. In addition, a random selection of 15 healthy blood donor samples were assayed for the presence of $\mathrm{Ph} 1$. All samples were negative for $B C R / A B L$ and positive for $A B L$, as expected; all K562 positive control samples indicated the predicted sensitivity. These results are also summarized in Table 1.

Representative analysis of clinical samples is shown in Figure 3. Panel A shows the analysis of an individual with clinical evidence of CML. The presence of a $\mathrm{B} 3 \mathrm{~A} 2 B C R / A B L$ is indicated by the 392-bp PCR product detected after one round of amplification (lane A1). Cytogenetic analysis of this patient confirmed the presence of a $\mathrm{Phl}$. Lanes A4 through A6 are the ABL, BCR/ABL primary, and $B C R / A B L$ secondary amplifications for the K562 spiked replicate control set, respectively. Figure $3 \mathrm{~B}$ shows the MRD analysis of a peripheral blood sample from a CML patient 211 days after BMT. Residual disease was detected as indicated by the presence of a 300-bp band, corresponding to a $\mathrm{B} 3 \mathrm{~A} 2 \mathrm{Ph} 1$, in the second round of PCR (lane B3). Panel C shows the analysis of a peripheral blood sample from an individual presenting with a clinical suspicion of CML. This sample was negative for the presence of either a $\mathrm{B} 2 \mathrm{~A} 2$ or B3A3 Ph1 after two rounds of PCR (lane C3). The sample RNA integrity was adequate as indicated by the presence of a 250 -bp $A B L$ PCR

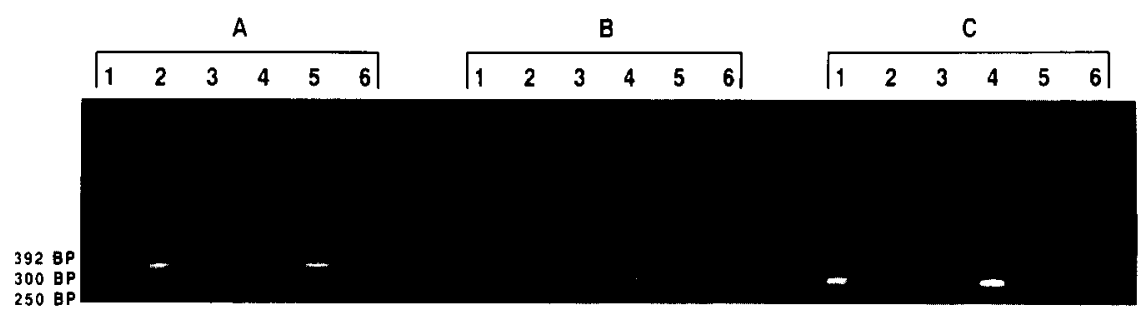

Figure 3. Nested primer PCR detection of Ph1 in patient samples. All sample sets are run in the following order: $(I)$ ABL control amplification, (2) $B C R / A B L$ first-round amplification, (3) $B C R / A B L$ second-round amplification, (4) $\mathrm{K} 562$ spiked $A B L$ control amplification, (5) K562 spiked $B C R / A B L$ first-round control amplification, and (6) K562 spiked $B C R / A B L$ second-round control amplification. (Set A) Patient sample analyzed for diagnosis of CML; patient is Phl positive (lanes A2 and A3). (Set B) CML patient sample analyzed after BMT for MRD; patient is $\mathrm{Ph} 1$ positive in the second round of amplification (lane B3). (Set C) Patient sample analyzed for diagnosis of CML; patient is $\mathrm{Ph} 1$ negative (lanes $A 2$ and A3). The patient RNA was of good quality (lane CI) and is capable of supporting an assay of predicted sensitivity (lane C6). 
product in lane $\mathrm{C} 1$. This patient RNA sample was capable of supporting a sensitive $B C R / A B L$ amplification as indicated by the detection of a $300-b p$ $\mathrm{B} 3 \mathrm{~A} 2$ band in the spiked replicate control reaction (lane C6). Cytogenetic analysis of this patient sample was negative for $\mathrm{Ph} 1$ but indicated the presence of an inversion on the long arm of chromosome 16 (q22q24) associated with acute myelomonocytic leukemia; this is a cytogenetic abnormality not associated with CML.

\section{Conclusions.}

Internally, this assay was $100 \%$ reproducible; an overall concordance rate of $\geqslant 95 \%$ was observed with other measurements (dilution studies, molecular analysis, cytogenetic analysis). Sensitivity was monitored in every assay. Assay components (enzymes, primers, buffers) were also internally controlled in each assay. Contamination of samples was monitored by duplicate sample analysis and by the inclusion of blank samples in each assay. This approach provides a very sensitive, reproducible, and rapid assay for the presence of Ph1-positive cells, which has utility not only for detection of minimal residual disease after treatment but as a tool for establishing a diagnosis of CML. More important, the steps outlined here for assay control can be adaptable to any PCR-based detection scheme.
This work was supported in part byR29DK43470 from the National Institutes of Health, Bethesda, MD. We thank the members of the greater Milwaukee hematology/oncology community for the referral of samples and for sharing with us the results of the corresponding cytogenetic analysis. We are also grateful to Daniel Bellissimo, $\mathrm{PhD}$, for preparing the cells for blind analysis.

\section{References}

1. Konopka JB, Watanabe SM, Witte ON: Cell 37:0135-1042, 1984

2. Roth MS, Antin JH, Ginsgurg D: Blood 74:882-885, 1989

3. Roth MS, Antin JH, Ash R, Terry V, Gotleib M, Silver S, Ginsburg D: Blood 79:276-282, 1992

4. Dobrovic A, Trainor KJ, Morley AA: Blood 72:2063-2065, 1988

5. Lee MS, Chang KS, Freireich EJ, Kantarjian HM, Talpaz M, Trujillo JM, Stass SA: Blood 72:893-894, 1988

6. Delage R, Soiffer RJ, Dear J, Ritz J: Blood 78:2759-2767, 1991

7. Thompson JD, Brodsky I, Yunis JJ: Blood 79:1629-1635, 1992

8. Lee MS, Kantatjian H, Talpaz M, Freireich EJ, Deisseroth A, Trujillo JM, Stass SA: Blood 79:1920-1923, 1992

9. Drobyski WR, Keever CA, Roth MS, Koethle S, Hanson G, McFadden P, Gottschall JL, Ash RC, van Tuinen P, Horowitz MM, Flomenberg N: Blood 82:2310-2318, 1993

10. Miyamura K, Tahara T, Tanimato $M$, Horishita $Y$, Kawashima K, Morishima Y, Saito H, Tsuzuki S, Takeyame K, Kodera Y, Matsuyama K, Hirabayashi N, Yamada H, Naito K, Imai K, Sakamaki H, Asai O, Mizutani S: Blood 81:1089-1093, 1993

11. Chomczynski P, Sacchi N: Anal Biochem 162:156-159, 1987 